A Mauricio Beuchot, con admiración y aprecio

Antonio López Eire

Universidad de Salamanca

\title{
La filosofía platónica de la Poética de Aristóteles
}

Las postmodernas humanidades de este nuevo siglo son un conjunto de disciplinas de más o menos venerable antigüedad en torno a la comunicación entendida como factor socio-político y filosófico. Es decir: el corazón de las nuevas humanidades, la Teoría de la comunicación, que coincide en parte con lo que antaño se denominaba Retórica, es la ciencia que se ocupa, por un lado, de la interacción social y política a través del lenguaje -y en esta área aparece como objeto de estudio esa especialísima forma de comunicación interactiva que es la literaria-, y, por otro, de la reflexión sobre todo lo humano y lo divino, ya que la reflexión es fundamentalmente lenguaje en acción y que la principal función del lenguaje es la comunicación que es siempre persuasiva aunque no siempre nos lo parezca.

Hoy en día sabemos que cuando filosofamos nos hablamos a nosotros mismos y tratamos de autopersuadirnos con el lenguaje. Eso es la filosofía y hasta la ciencia más presuntuosa de exactitud y rigor: mero discurso persuasivo hecho con palabras destinado siempre al prójimo aunque lo hayamos generado en la más recóndita soledad del soliloquio. La realidad que haya 
tras las palabras de nuestro persuasivo discurso es otra cuestión. Pero toda filosofía es lenguaje en acción, o sea retórica, y no puede ser otra cosa más. Vamos a verlo seguidamente estudiando la aplicación que hizo Aristóteles de la filosofía platónica (o de la retórica platónica, si se prefiere) al estudio de la realidad poética, a la contemplación y explicaciớn discursiva y persuasiva de la poesía.

Así pues, el propósito más concreto de las páginas que siguen, efectivamente, es mostrar cómo la Poética, al igual que otras obras del Estagirita, es el resultado de la reflexión sobre la poesía de un filósofo que combinaba la observación de la realidad empírica con una versión particular de la metafísica platónica consistente en afirmar la inmanencia de la "forma" (en griego, eîdos) en el ser individual percibido por los sentidos. ${ }^{1}$ Aproximaremos así filosofía y poética, cumpliendo con ello uno de los objetivos deseados por los más modernos planteamientos de la modernísima Teoría de la comunicación.

Según Aristóteles, la satisfacción intelectual y estética que la poesía proporciona deriva de la perfecta ordenación unitaria de la estructura de ésta, que muestra a los ojos del curioso observador la misma organicidad que se detecta en las "formas" de los seres vivos, las cuales son encarnaciones en la materia de las Ideas platónicas que habitaban en el mal precisado lugar supraceleste o hyperouránios en que las situaba el divino filósofo.

Para entender cabalmente la Poética y toda la filosofía de Aristóteles es preciso partir del principio de que sólo la "forma”, el eîdos, configura la unidad de la sustancia, le confiere su ser propio, permite responder a la pregunta "¿qué es esa sustancia?", sólo ella es objeto de la ciencia y produce satisfacción intelectual y estética en el arte y en la poesía.

Estas "formas" que informan las cosas y coinciden con sus causas finales (por ejemplo: la "forma" del pericarpio es la pro-

${ }^{1}$ Quiero hacer constar mi agradecimiento a la DGICYT por su apoyo económico (PB 96/1268). Cic., Fin. V, 2. Acad. II, 119. Top. I, 3. 
pia y adaptada a su fin de envolver la semilla de los frutos) son ahora ya las "formas" aristotélicas, pero eran anteriormente las "ideas" de Platón, idénticas a sí mismas, principios inmutables del ser, descendidas, según la nueva metafísica del Estagirita, desde el lugar supraceleste a este mundo real.

Aristóteles no compuso su estupendo tratadito titulado Poética partiendo de cero, porque contaba con conceptos anteriormente en curso y más o menos fundados sobre poesía y sobre el discurso persuasivo, con la especulación de los sofistas sobre el inmenso poderío del discurso poético y retórico, en prosa o en verso -que ésta es según Gorgias la única diferencia de la poesía, el ser discurso sometido a metro-,${ }^{2}$ y además con la enseñanza impartida a lo largo de veinte años por su maestro Platón, que tenía también sus ideas sobre el tema. El Estagirita llegó a Atenas con diecisiete años el 367 a. J. C. (había nacido el 384 a. J. C.) y fue discípulo del "divino filósofo" hasta la muerte de éste el año $348 / 7$ a. J. C.

Yo diría que, por lo que se refiere al contenido de su Poéti$c a$, Aristóteles depende sin duda alguna de una doctrina anterior que en gran medida es la de los sofistas sobre la esencia y los efectos del lenguaje y la de Platón, que había acomodado, con no pocas alteraciones, la lucubración sofística sobre ese tema, a su particular filosofía ética, política y metafísica.

Los conceptos aristotélicos de mímesis, apáte, poder psicagógico de la palabra, e incluso ese tan esencial en su Poética de la unidad y cohesión de la obra poética como principio fundamental de toda poesía tienen ilustres precedentes en el "divino filósofo" y aun antes en los sofistas. Gorgias en el Encomio de Helena, por ejemplo, y Platón en numerosos pasajes de sus diálogos trataron esta. temática con anterioridad al Estagirita.

${ }^{2}$ Grg. Hel.=Fr. B 11, 9 D-K "la poesía en su totalidad, la considero y denomino discurso sometido a metro". 
Recordemos, a título de mero ejemplo, el famoso pasaje del recién referido discurso gorgiano, ${ }^{3}$ en el que se establece la comparación entre la poesía y el discurso con la pintura y las estatuas, obras artísticas que deben ser todas necesariamente unitarias y psicagógicas, es decir, deben reflejar una unidad temática y deben afectar emocionalmente a sus contempladores, oyentes o lectores:

pero los pintores, cuando a partir de muchos colores y cuerpos llevan a cabo a la perfección un solo cuerpo y figura, deleitan la vista; y la fabricación de imágenes y la elaboración de estatuas procuran a los ojos una dulce enfermedad. Así unos espectáculos por su naturaleza apenan la vista y otros, en cambio, la deleitan. Muchas visiones provocan en muchos hombres el amor y el deseo de muchas acciones y cuerpos.

En estas palabras se encierran muchos temas de poética que interesaron más tarde a Platón y Aristóteles, como el de la mímesis, el de la unidad de la obra artística y poética, el del efecto psicagógico del arte y el de la finalidad y causa de todo arte, incluido el poético, que no es sino el deleite de índole -según ambos filósofos-fundamentalmente cognitiva o intelectual. Pero Gorgias no hace sino esbozarlos. Quien de verdad los aborda por extenso y filosóficamente, abriendo así el camino de indagación filosófica de dichos temas a Aristóteles en su Poética, fue realmente el maestro de este último, o sea, Platón.

Hemos de ver que esto es así centrándonos, a título de ejemplo, en ese principio que obsesivamente repite Aristóteles a lo largo de su obrita: ${ }^{4}$ el de la cohesión y unidad orgánica de la

${ }^{3}$ Grg. Hel.=Fr. B 11, 18 D-K. Sigo, sin embargo, el texto de D. M. MacDowell, Gorgias Encomium of Helen, Bristol, Bristol Classical Press, 1982.

${ }^{4}$ S. Halliwell, Aristotle's Poetics, Londres 1986, 283 'The unity of Aristotelian work of art reflects the unity of its object...Aristotle's single-minded and repeated insistence on unity". 
obra poética, que consiste, según el Estagirita, en una buena trabazón de sus partes argumentales o, si se prefiere, en el ensamblaje perfecto de los sucesos poéticamente elaborados en un todo unitario, ${ }^{5}$ en la cohesión interna resultante de la aplicación de los principios de necesidad y/o probabilidad a los argumentos, ${ }^{6}$ con lo que se excluyen de la tragedia lo irracional o fortuito y la innecesaria maldad, ${ }^{7}$ en la unidad de tiempo que convierte la acción dramática en "abarcable bajo un giro de sol", 8 en la perfecta combinación de "la unidad y la integridad", 9 en la nítida delimitación de las partes (principio, parte media y fin) dentro de un todo unitario, ${ }^{10}$ y en la unidad orgánica de la poesía, una unidad que es comparable a la de los animales o los cuerpos de los seres vivos, ${ }^{11}$ condición sine qua non de la obra poética, pues sólo así es capaz ésta de producir el placer que le es propio. ${ }^{12}$ También se observa externamente este principio de unidad y cohesión de la poesía, por ejemplo, en la recurrencia que necesariamente acarrea el ritmo poético, que hace pensar a quién lo percibe "cuándo volverá de nuevo

5 Arist. Po. 1450a 32 y 1450b 22 "trabazón de acontecimientos". Cf. Pl. Phdr. 268d 4. Cra. 425a. Grg. 503e, 506e. Prm. 137c.

6 Arist. Po. 1451a 12 "en virtud de lo probable o lo necesario". 1456a 23 "pues eso también es verosímil, como dice Agatón, ya que es verosímil que ocurran muchas cosas también contra la verosimilitud". Cf. Pl. Phdr. 264b. Tht. 149c. Ti. 40e.

7 Arist. Po. 1461 b 19 "es correcta la crítica a la irracionalidad y la maldad, cuando, sin que haya necesidad en absoluto, el poeta hace uso de lo irracional, como Eurípides con el personaje Egeo, o de la maldad, como hace el mismo poeta en el Orestes con el personaje de Menelao".

${ }^{8}$ Arist. Po. 1449b 13 “abarcable bajo un giro de sol".

9 Arist. Po. 1451 a 3 "la unidad y la integridad".

10 Arist. Po. 1450b 26 "completo es lo que tiene principio, medio y fin". Cf. Pl. Phlb. 31a. Prm. 137d. Lg. 715e.

11 Arist. Po. 1451a 4 "como en los cuerpos y en los seres vivos". Cf. PI. Phdr. 264c. Grg. 506d. R. 401a. Ti. 32d-33a; 87c.

12 Arist. Po. 1459a 20. 
el mismo esquema", ${ }^{13}$ y en la metáfora, que es el resultado de la aplicación de un ingenio bien dotado por naturaleza a la contemplación de lo semejante entre dos términos. ${ }^{14}$

Pues bien, el principio de la coherencia y la unidad estructural, orgánica, de la obra poética, exigible en toda arte mimética, a saber:

esa piedra de toque que convierte a la épica en un género inferior a la tragedia ${ }^{16}$ pero que hizo grande a ese poema homérico excepcional que es la Ilíada, ${ }^{17}$ ese principio que exige que hasta el Coro intervenga en una tragedia como un actor más ${ }^{18}$ y que los caracteres de los personajes estén siempre subordinados a las acciones, ${ }^{19}$ esa norma estricta que convierte a las partes del todo en inamovibles e inalterables, ${ }^{20}$ es a todas luces un tema filosófico de innegable cuño platónico.

Ahora bien, al tratar del problema de las relaciones del discípulo Aristóteles con su maestro Platón, conviene dejar previamente bien sentados dos principios que hoy día parecen claros: uno, que la historia evolutiva, la Entstehungsgeschichte por decirlo con Werner Jaeger, del pensamiento aristotélico desde sus

13 Arist. Rh. 1408b 24 "cuándo volverá de nuevo el mismo esquema”. Cf. PI. Lg. 665a. En este pasaje define Platón el "ritmo" como "el orden en el movimiento".

14 Arist. Po. 1459a 6 "ya que esto es lo único que no puede tomarse de otro y es señal de talento, pues metaforizar bien es contemplar las semejanzas".

15 Arist. Po. 1451a 30 "al igual que en las demás artes de imitación la unidad de la imitación resulta de la unidad de su objeto".

${ }^{16}$ Arist. Po. 1462b 3 "además es menos unitaria la imitación de las epopeyas".

17 Arist. Po. 1459b 14 "la Ilíada, como poema simple y de pasiones". 1457a 29 "la Ilíada es una sola frase por la ligazón de sus partes".

18 Arist. Po. 1456a 26 "y al coro hay que concebirlo como uno solo de los actores, y debe ser una parte del conjunto e intervenir en la acción, no como en Eurípides, sino como en S6focles".

19 Arist. Po. 1450a "pues la tragedia es imitación no de hombres, sino de acciones".

20 Arist. Po. 1451a 32 "y que las partes de las acciones estén de tal modo ensambladas entre sí, que, si se se cambia de lugar o se suprime una de ellas, se altere y conmueva también el conjunto". 
presuntos orígenes puramente platónicos a su madurez empírica no es hoy ya así de sencilla y lineal como la entendió en su día el ilustre filólogo alemán. Aristóteles fue más bien desde un principio platónico y empírico a un tiempo, fue aristotélico siempre. Y dos, que aunque discrepemos un tanto de la hoy ya inadmisible cronología propuesta por Jaeger para explicar la copiosa y variada producción aristotélica, pese a ello, sigue siendo exacta su concepción de la filosofía de Aristóteles como una filosofía no dogmática ni cerrada, estancada o monolítica, sino abierta, cambiante, fluida, evolutiva y no carente de incoherencias, desacuerdos y fisuras, en total y frontal contradicción con la tradición medieval que nos presenta la obra del Estagirita como un sistema acabado, clausurado y redondo, configurado de una vez por todas desde sus orígenes y sin indicio alguno de haber experimentado una evolución cronológica interna.

Aristóteles es, en efecto, un filósofo mesurado que cambia de estilo $^{21}$ y tono en sus escritos según el tema, el propósito y el destino de lo en ellos tratado, ${ }^{22}$ y que antes de abordar una cuestión ofrece una revisión crítica de las opiniones que sobre ella han expresado sus predecesores o somete a riguroso escrutinio los diferentes sentidos en que se dice una misma palabra cuyo significado es objeto de estudio o se enfrenta con coraje a las más o menos aparentes aporías o dialoga consigo mismo tratando de hacer encajar las teorías con los hechos de experiencia o

${ }^{21}$ El "ăureo río de su discurso", tal como Cicerón se refiere a la elocuencia aristotélica (Cic. Acad. II, 119) y la "suavidad de su estilo", según juicio de Quintiliano (Quint. X, 1, 83), no sólo debieron ser perceptibles en sus obras exotéricas o destinadas a la publicación, sino que también se perciben parcialmente, a pesar de las limitaciones impuestas por su función, en las filosóficas (lógoi katà philosophían) o destinadas a las clases y al estudio de la escuela.

22 H. Diels, "Über das Dritte Buch der Aristotelischen Rhetorik", Abhandlungen der Königlichen Akademie der Wissenschaften zu Berlin, PhilologischHistorische Klasse, vol. IV(1886) 3-34; reproducido en R. Stark (ed.), Rhetorika. Schriften zur aristotelischen und hellenistischen Rhetorik, Hildesheim 1968, 2 "einestheils hat Aristoteles in seinen Lehrschriften... oft einen sehr verschiedenen Stil und Ton angewandt". 
adaptando su pensamiento a categorías conceptuales clara y sólidamente definidas, siempre evitando la violencia o el forzamiento.

Precisamente por esa misma maleabilidad, ductilidad y fácil avenencia o acomodación de su inteligencia a los principios de su mesurada y sana metodología, Aristóteles no es un filósofo de una pieza o monolítico, dogmático, tozudo y pertinaz, sino que, como demostró admirablemente Werner Jaeger, ${ }^{23}$ fue paso a paso ${ }^{24}$ investigando las cuestiones que acuciaban su casi infinita curiosidad, planteándose problemas y tratando de resolverlos, y por tanto modificando continuamente sus puntos de vista, ${ }^{25}$ para así, poco a poco, ir construyendo su sistema filosófico, que al final resultó tanto más coherente y compacto cuanto menos lo tuvo desde un principio por definitivo su forjador. ${ }^{26}$ Como hizo ver claramente Paul Moraux, a pesar de su predilección por la síntesis y del inmenso poder de su genio, no dejó construido un sistema rígido y bien delimitado. ${ }^{27}$

en $P$.

${ }^{23}$ A.-H. Chroust, "Die ersten dreissig Jahren moderner Aristotelesforschung", "Heute wird niemand Jaegers Hauptthese ernsthaft in Frage stellen".

${ }^{24}$ Aunque P. Moraux considera que hay en Aristóteles ciertas antinomias que no tienen nada que ver con la evolución de su pensamiento, añade que el cambio producido en éste no debió ser súbito ni violento. Cf. P. Moraux, "Die Entwicklung des Aristoteles", en P. Moraux (ed.), Aristoteles in der neuren Forschung, Darmstadt 1968, 94 "Dieses (sc. sein Denken) scheint kaum plötzlicher Umkehrung oder heftigem Umschwung ausgesetzt gewesen zu sein".

${ }^{25}$ Según F. Dirlmeier, Aristóteles fue siempre platónico y empírico a la vez, de modo que no habría evolucionado desde un primitivo platonismo al empirismo, como intentaba demostrar Jaeger. Cf. F. Dirlmeier, “Aristoteles" en P. Moraux (ed.), Aristoteles in der neuren Forschung, Darmstadt 1968, 144-57. D. W. Graham, Aristotle's Two Systems, Oxford 1987.

${ }^{26}$ W. Jaeger, Aristoteles. Grundlegung einer Geschichte seiner Entwicklung, Berlín 1923; Aristóteles. Bases para la historia de su desarrollo intelectual, trad. esp., México 1946; tercera reimpresión, Madrid 1993, 458 "a pesar de la coherencia interna de su evolución, entrañó ésta un decisivo desplazamiento del centro de gravedad en dirección de la ciencia positiva".

27 P. Moraux, "Die Entwicklung des Aristoteles", en P. Moraux (ed.), Aristoteles in der neuren Forschung, 94 "hat er niemals, trotz seiner Vorliebe für 
Pues bien, la Poética, al igual que la Retórica y buena parte de la filosofía del Estagirita, es en gran medida una respuesta al desafío de la filosofía de su maestro, una filosofía ética, política y metafísica que se pasó de la raya en rigurosidad y -hay que confesarlo- dogmatismo. Pero es la respuesta de un excelente discípulo que aprendió muchísimo de su maestro y que es en gran medida platónico. La Poética es la típica obra que revela al Aristóteles platónico-empírico.

Una lectura atenta del tratado, en efecto, nos hace ver en él una defensa apasionada de la legitimidad del disfrute de la poesía, cuyo fin es el placer, el placer que le es propio en cuanto imitación, ${ }^{28}$ porque la poesía posee un alto status intelectual (es más filosófica y seria que la historia) ${ }^{29}$ y moral (ya que nada puede haber de inmoral en imitar las cosas tal como son o se dice que son o debieran ser). ${ }^{30}$

Pero pese a sus contundentes respuestas a Platón, Aristóteles es un filósofo platónico. Todos esos principios fundamentales de la poesía que hace poco mencionábamos y que constituyen el centro de gravedad de la Poética aristotélica, como su unidad, su estructura compositiva a base de principio, parte media y fin, su cohesión interna en virtud de los principios de necesidad o probabilidad impuestos en los argumentos, y su organicidad, explicada a través de la analogía observable entre una obra poética unitaria y un ser vivo, ${ }^{31}$ todo eso es doctrina platónica de pura cepa bien asimilada por su inteligente discípulo.

die Synthese und der Kraft seines Genies, ein starres und scharf begrenztes System aufgestellt".

${ }^{28}$ Arist. Po. $1448 \mathrm{~b} 18$.

${ }^{29}$ Arist. Po. 1451 b 5.

${ }^{30}$ Arist. Po. $1460 \mathrm{~b} 10$.

31 Por ejemplo: para encontrar en Platón referencias claras a la obra poética, a su cohesión a través del principio de necesidad y a la semejanza de la poesía con un ser vivo, sólo hace falta leerse uno detenidamente el Fedro. Cf. respectivamente Pl. Phdr. 268d 4; 264b y 264c. Otros diálogos de referencia pueden verse en S. Halliwell, Aristotle's Poetics, 333. 
Y es que ocurre que, aunque el Estagirita no acepta la Teoría de las Ideas de su maestro, para él la "forma", el eîdos de las cosas, no es un mero concepto subjetivo, sino que está objetivamente en la realidad de los individuos, pues ninguna materia es representable sin "forma" y por tanto la "forma" es tan real, tan increada y tan eterna como la materia. Pero además esta forma, a semejanza de las Ideas platónicas, hace posible comprender la cosa individual en que se encuentra y, en la Naturaleza, es una fuerza que actúa inconscientemente con una finalidad y en el arte lo hace conscientemente.

La causa formal y la causa final son idénticas en el dominio de la Naturaleza y así la realización de la causa formal de una cosa natural es al mismo tiempo el cumplimiento de su finalidad o causa final (entelequia). La causa final última y la forma suprema del universo son una sola y constituyen el fin de todo: el Primer Motor inmóvil, el Dios aristotélico que, aunque no es creador de la materia (pues la materia es increada) es el acto puro, el "pensamiento del pensamiento", nóesis noéseos, que da unidad a las sustancias de la Naturaleza y del mundo. Por esa razón la obra de arte en general y la obra poética en particular, que son imitaciones de la Naturaleza, han de ser unitarias y coherentes.

La "materia" (etimológicamente, "madera del bosque", hyle) es el límite inferior de los seres o sustancias, pero esta materia sin forma nos es incognoscible por sí misma (ágnostos kath' hautén), puede recibir todas las formas posibles y sufrir todos los cambios, no está ahormada, es arrúthmistos, y por tanto hay en ella un desorden general, sometida como está a un cambio perpetuo.

Sin embargo, en el más alto escalón de las sustancias está la "forma", eîdos, que es la marca individual que confiere a cada cosa ser propio, la respuesta a la pregunta tò tí ên eînai, a la quididad de cada cosa, pero esta "forma" no se encuentra sola (excepción hecha del Primer Motor) sino en la materia. Ahora 
bien, entre la "materia" y la "forma" hay gran diferencia de categoría, pues la esencia de una sustancia es su "forma" y lo es tanto más cuanto más perfectos son los objetos. Es la "forma" la que manda en la estructura de la "materia" en la que está fija o se va a fijar, mientras que la pobre e infeliz "materia" se adapta a la "forma" como a su fin. Y así el estado en el que la "materia" alcanza su perfección relativa es la entelequia, la entelékheia, en cuanto que es la realización de un fin. Este fin o "causa final" explica las "formas" de los objetos naturales y artísticos.

El fin propio de un ser es realizar su forma, el fin propio del hombre es el de ser lo más hombre posible, el fin de toda la Naturaleza es el de ser lo mejor posible (tò eû, tò béltiston). En la Historia de los animales leemos una frase sobrecogedora que, en traducción al español, dice así: "y aquel fin por el que se ha constituido o ha llegado a ser ha ocupado el puesto de la hermosura". ${ }^{32}$ Es decir, el filósofo ve la belleza en un animal, en un ser vivo, porque sabe apreciar su "forma" como resultado de una "causa final" que "no ha operado al azar sino con vistas a un determinado objetivo". ${ }^{33}$ Pues bien, aquí, en medio de esta teleología aristotélica por la que existe una finalidad, una "causa final" en el universo que se plasma en la "forma" compacta y bella de los seres vivos y orgánicos, una "forma" o "causa final" que se realiza mirando al "bien" y a "lo mejor" porque la Naturaleza es inteligente, consciente y está dotada de una providencia oculta en la esencia de las cosas por la que éstas tienden hacia lo óptimo, lo mejor posible (tò ê̂, tò béltiston) y lo "bello" o la "belleza", cuyas "más importantes facetas son el orden, la proporción y la delimitación", ${ }^{34}$ en medio de todos estos conceptos y principios - insisto- percibimos intacta e incólume la filosofía del divino Platón.

32 Arist. PA 645 a 25.

33 Arist. PA 645 a 23.

${ }^{34}$ Arist. Metaph. 1078 a 36. 
Recordemos que las Ideas del "divino filósofo", al ser inmutables, inmóviles, inertes, trascendentes y causa de las cosas sensibles, tenían que ser necesariamente "causas finales". Y que el conjunto de las Ideas platónicas formaba un sistema coherente y lógico regido por una finalidad suprema, un principio teleológico, a saber: la Idea del Bien, que era la suma de las causas finales, la última, definitiva y más profunda razón del Universo, identificable con la Idea de lo Bello, con la Belleza absoluta. ${ }^{35}$ Y que en una última etapa de su pensamiento que aparece parcialmente bosquejada en el Timeo y en el Filebo Platón hacía derivar todas las Ideas de una primera "unidad originaria". La Idea del Bien, idéntica a la Idea de lo bello y unitaria en sí misma, sería el principio teleológico que daría unidad a todas las Ideas, que derivarían de ella.

Pues bien, Aristóteles bajó a este mundo el mundo de las Ideas de Platón, de esas esencias eternas independientes del pensamiento humano, que eran el único "ser" frente a la cambiante realidad de las cosas. Y esas Ideas platónicas Aristóteles las hizo encarnar como "formas" en la materia sensible, de tal manera que las mencionadas "formas" de una cosa natural significaban al mismo tiempo su esencia y el cumplimiento de su finalidad (entelequia), por lo que en la Naturaleza orgánica nos encontramos con seres tan sumamante unitarios y cohesionados en sus partes, que tienen idénticas su "causa formal" y su "causa final". Y así debe ser la obra de arte, pues en su realización la "forma" y la "causa final" del artefacto, idénticas una a la otra, han de pasar de la mente del artista a la "materia", unificándola y proporcionándole así un alto grado de cohesión interna, que es asimismo en el fondo un altísimo grado de operatividad.

Ahora bien, si la Naturaleza refleja para cada cosa una unidad bien compacta, orgánica y funcional, una forma, una fina-

${ }^{35}$ Pl. Smp. 210e. 
lidad, en todas las artes miméticas la mímesis o imitación ha de ser de un solo objeto y en consecuencia la tragedia lo será de una sola acción. ${ }^{36} \mathrm{Y}$, por otro lado, la clave de la semejanza de la obra artística a la obra de la Naturaleza está en el hecho de que, como el propio Aristóteles nos explica en su $D e$ anima, la misma teleología impera en la naturaleza y en la mente. ${ }^{37}$ La Naturaleza y el arte tienden ambas al "bien", a "lo mejor", a la óptima organización de su material. Y esto es así porque la Naturaleza no hace nada en vano ni irracionalmente $^{38}$ y porque el arte (dado que también la mente, como natural que es, obra siempre con vistas a algo) imita a la Naturaleza. ${ }^{39}$

Para el Aristóteles platónico y empírico a un tiempo las Ideas transcendentes separadas de las cosas, tal como las concebía su maestro, han pasado a ser "formas" inmanentes del ser individual que conocemos a través de los sentidos pero cuya esencia, ese tò ti ên einai, se la brindan ellas. La "forma" aristotélica es, respecto de cada cosa individual, exactamente equivalente a las Ideas platónicas por cuanto que sólo la "forma" de una cosa hace posible saber algo acerca de ella. El conocimiento científico no versa sobre los individuos, sino que sólo puede versar sobre lo general, sobre los conceptos que forman la esencia de los individuos. Por eso una obra de arte, una obra poética, una tragedia, es digna. Lo es porque produce el placer intelectual de conocer no lo que hizo Alcibíades, sino lo que ocurrió o pudiera haber ocurrido a un ser humano en virtud de

- 36 Arist. Po. 1451 a 30 "así pues, al igual que en las demás artes de imitación la unidad de la imitación resulta de la unidad de su objeto, así también es preciso que el argumento, puesto que es imitación de una sola acción, lo sea de una sola y que ésta sea completa, y que las partes de las acciones estén de tal modo ensambladas entre sí, que, si se se cambia de lugar o se suprime una de ellas, se altere y conmueva también el conjunto. Pues aquello que por estar o no estar adjunto a algo no produce efecto apreciable alguno, eso no es en absoluto una parte del todo".

${ }^{37}$ Arist. de An. 415e 17 "pues de la misma manera que la mente obra con vistas a algo, de la misma manera también la Naturaleza".

38 Arist. Cael. 271a 33. 291 b 13.

${ }^{39}$ Arist. Phys. 194a 21. Meteor. 381 b 6. 
la necesidad o la verosimilitud de los acontecimientos y de las acciones. ${ }^{40}$ Parece, pues, claro que Aristóteles dignifica la poesía elevándola de lo particular a lo genérico, situándola en el mundo de las formas, de las ideas.

Y por otro lado, pesa en el Estagirita la influencia de la metafísica platónica (de la que no se diferencia tanto la aristotélica por lo menos en la base: la realidad objetiva de las "formas" en cuanto esencia de las cosas), en el tema de la identidad de la "forma" y de la "causa final" en la Naturaleza y en el arte, pues la forma de una cosa es el cumplimiento de su finalidad (entelequia). La tragedia, por ejemplo, terminó por adquirir —según el pensamiento teleológico de Aristóteles- su forma definitivamente apropiada ${ }^{41}$ y asimismo el metro más apropiado a su finalidad. ${ }^{42}$

Por eso, dada la coincidencia de "forma" y "causa final" en la Naturaleza y en el arte, y garantizado el paralelismo del arte respecto de la Naturaleza, como esta última refleja en todos los seres una unidad, una forma, una finalidad, una cohesión, un buen ensamblaje de las partes, una organicidad que, en última instancia proceden de la unidad de la causa motora (el Primer Motor) y la finalidad de todo movimiento, identidad que explica la unidad del mundo, la obra de arte, la obra poética, la tragedia, tiene que ser una, coherente, bien ensamblada y orgánica como los seres vivos. Y todo esto es en muy buena medida

${ }^{40}$ Arist. Po. 1451b 4 "la diferencia estriba en que uno narra lo sucedido y el otro cosas tales que podrían suceder. Por lo cual precisamente la poesía es más filosófica y seria que la historia, pues la poesía narra más lo general, la historia lo particular. Lo universal reside en plantearse a qué clase de hombre le corresponde decir o realizar tales o cuales cosas en virtud de lo verosímil o lo necesario, un objetivo al que aspira la poesía a pesar de imponer nombres propios a sus personajes. Lo particular, en cambio, está en contar qué hizo Alcibíades o qué le paso".

${ }^{41}$ Arist. Po. 1449a 14 "y, tras experimentar muchos cambios, se detuvo una vez que hubo alcanzado su propia naturaleza".

42 Arist. Po. 1449a 23 “pero al surgir la conversación, la naturaleza misma encontró el metro apropiado, pues el yambo es en muy gran medida conversacional". 
platónico, pues, a mi modo de ver, la metafísica de Aristóteles es una síntesis de la teoría platónica de las ideas y de una concepción empírica del mundo muy suya, muy aristotélica. Pero volvamos a la Poética.

Ya en el $\mathrm{Fedro}^{43}$ leemos que la tragedia (y cabe suponer que toda obra poética) es una estructura bien ensamblada y armónica de elementos que encajan bien unos con otros y dentro del conjunto en el que se integran: "Fedro. - Y ésos (sc. Sófocles y Eurípides) creo que se burlarían de un individuo que se imaginara que la tragedia es otra cosa que no sea el ensamblaje de esas piezas de forma bien ajustada entre ellas y encajado en la estructura del todo".

Las palabras clave en este pasaje son sústasis, el "ensamblaje", el "entramado", la "trabazón", el término favorito de Aristóteles para definir la perfecta integración de unas partes de la tragedia con otras y de todas ellas con el conjunto que forman, y el correspondiente término verbal para designar con las pertinentes categorías verbales de tiempo, aspecto y voz la realización de dicha acción es sunístasthai. Examinemos primeramente la voz sústasis en la Poética: "el más importante de estos elementos es el entramado (sústasis) de las acciones". 44

Con esta palabra clave, de clara prosapia platónica, Aristóteles insiste, siguiendo las huellas de su maestro, en la necesidad de que la obra poética sea una unidad de partes bien trabadas y cohesionadas. Justamente este término sústasis alterna con la voz súnthesis, para designar la "composición estructural", la "estructura" que han de configurar las acciones que como partes constituyen la trama del argumento: "pues llamo aquí argumento a la composición de las acciones".45

\footnotetext{
43 Pl. Phdr. 268d 3.

${ }^{44}$ Arist. Po. 1450a 15.

45 Arist. Po. 1450a 4.
} 
La voz sústasis es un nombre verbal en -sis correspondiente al verbo en voz media sunistasthai, que, por supuesto, al igual que hemos visto en Platón, también lo emplea Aristóteles para referirse a la realización de la ensambladura o trabamiento requerido en la obra poética: "los que hacen sus primeros ensayos en poesía logran acertar antes con el lenguaje y los caracteres que con el ensamblaje (sunistasthai) de las acciones". 46

Utiliza también Aristóteles el verbo en voz activa, sunistánai, para referirse a la acción de "componer la trama" de los argumentos de las tragedias: "a continuación de lo que acabamos de decir, habría que hablar de aquello a lo que deben aspirar y de aquello de lo que se deben guardar los compositores (sunistánai) de argumentos, así como de cuál es el origen del efecto de la tragedia". 47 "Es menester que el poeta dé trabazón (sunistánai) a los argumentos y los remate por medio de la elocución a base de ponerlos lo más posible delante de los ojos". 48

La frecuencia de aparición de las voces sunístemi (16), sústasis (13) y sústema (1) es significativa del interés que prestaba Aristóteles, siguiendo en ello las enseñanzas de su maestro, al tema esencial en poética de la trabazón de la estructura del poema. ${ }^{49}$

La cohesión interna propia de un todo cuyas partes se integran ajustada y armónicamente es lo que hay que ver en el concepto aristotélico de sústasis referido a la obra poética, un concepto que ya Platón aplicaba a toda obra salida de las manos de un artesano, pero también, naturalmente, a toda la realidad en cuanto reflejo del mundo de las ideas y en par-

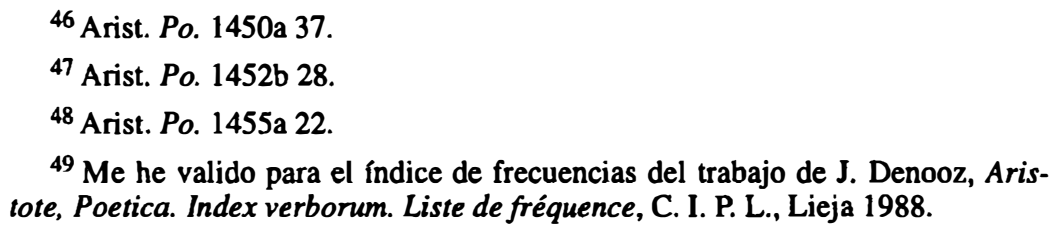

${ }^{49} \mathrm{Me}$ he valido para el índice de frecuencias del trabajo de J. Denooz, Aristote, Poetica. Index verborum. Liste de fréquence, C. I. P. L., Lieja 1988. 
ticular de la idea del Bien, que es como el sol de las ideas ${ }^{50}$ y coincide con las ideas de Belleza, Simetría y Verdad: ${ }^{51}$

como, por ejemplo, si quieres ver a los pintores, arquitectos, constructores de naves, y a todos los demás artesanos, al que quieras de ellos, cómo cada uno de ellos dispone ordenadamente los materiales que va colocando y los fuerza además a que ajusten y encajen armónicamente uno con otro hasta que el todo resulte un objeto bien ensamblado, y por ello ordenado y embellecido. 52

La composición artística da como resultado un objeto cuya belleza y funcionalidad consisten en la armonía, la proporción, el orden y el perfecto ensamblaje de las partes en el todo. Y a estas facetas se añade la de la delimitación. En un pasaje de la República se afirma, en efecto, que la dimensión ideal de una ciudad es aquella que es grande sin perder su unidad: ${ }^{53}$ “- ¿Qué límite? - Me imagino dije yo, que éste: acrecentar la ciudad hasta que creciendo no se resista a ser una, pero más allá no".

La misma relación ordenada, proporcional y delimitada de las partes con respecto al todo se observa, como ya hemos teni-

${ }^{50} \mathrm{Pl}$. R. 509b 2 “-Afirmarás, creo yo, que el sol procura a los objetos visibles no sólo la facultad de ser vistos, sino también el nacimiento, el crecimiento y la alimentación, sin que él sea la razón de su nacimiento. - ¿Pues cómo iba a serlo? -Asimismo reconocerás que los objetos cognoscibles cuentan con la facultad de ser conocidos gracias al bien, pero que además el ser y la esencia los poseen súplementariamente también gracias a aquel, sin que el bien sea esencia, sino que está aun allende la esencia con majestad y poder".

${ }^{51} \mathrm{PI}$. Phlb. 64e 5 "pero en realidad el poder del bien se nos ha refugiado en la naturaleza de la hermosura, pues la mesura y proporción sin duda suelen resultar en todas partes belleza y virtud". Pl. Phlb. 65a 1 "así pues, si no podemos con una sola idea dar caza a la bondad, habiéndola tomado con tres, belleza, proporción y verdad, digamos que a eso como una sola cosa correctísimamente lo haríamos responsable de las características de la mezcla y por eso, por ser bueno, ella ha resultado asî".

52 PI. Grg. 503e 4.

53 Pl. R. $423 \mathrm{~b} 8$. 
do ocasión de apuntar, en la definición de las facetas de la belleza que da Aristóteles en la Metafísica: "las especies más importantes de la belleza son el orden, la proporción y la limitación, que sobre todo las ciencias matemáticas ponen de manifiesto". 54

Ahora bien, Platón en el Fedro no sólo había de jado clara la necesaria cohesión estructural entre las partes y el todo en la obra poética, sino que además había comparado el discurso ideal a un ser vivo, orgánico, compuesto de cabeza, tronco o parte media y extremidades, constituido por partes bien proporcionadas mutuamente y en relación con el todo:

Sócrates. - Pero esto - creo yo- sí que lo podrías afirmar: que todo discurso tiene que estar constituido como un ser vivo, provisto de un cuerpo que le pertenezca, de manera que no esté desprovisto ni de cabeza ni de pies, sino que tenga parte media y extremidades perfilados de tal forma que guarden una justa proporción entre ellos mismos y en relación con el todo. ${ }^{55}$

Una vez más nos topamos con el concepto de sústasis, esta vez a través de la forma de perfecto sunestánai (Aristóteles utiliza cinco veces las formas de perfecto de sunístemi en la Poética con este mismo significado) ${ }^{56}$ para referirse a la bien trabada constitución estructural del discurso retórico. Pero además aparece la comparación de la trabazón estructural del discurso retórico -estructuralmente comparable al argumento poético en cuanto que ambos están artísticamente elaborados- con la organicidad del animal que, en cuanto ser vivo, se diferencia de los enseres, de las cosas inanimadas e inorgánicas (prágmata).

Quisiera llamar la atención sobre el hecho de que Aristóteles en un pasaje de su Poética en que reproduce la referida compa-

54 Arist. Metaph. 1078a 37.

55 Pl. Phdr. 264c 2.

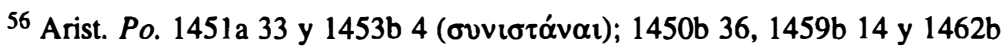

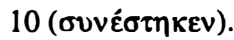


ración platónica, vuelve a hacer cohabitar las voces zôion, "ser vivo", y sunistemi, "ensamblar", "componer". Veámoslo: "es más: puesto que lo hermoso, animal o toda cosa que lo sea, compuesto de algunas partes, no sólo debe tenerlas ordenadas, sino también contar con una cierta extensión que no sea cualquiera al azar". ${ }^{57}$

La sústasis a la que se refiere Aristóteles en la Poética no es una composición cualquiera, sino una muy bien ensamblada y trabada composición de partes que desempeñan funciones coordinadas y construyen un conjunto asimismo coordinado, por lo que a lo que más se parece es a la constitución de un ser vivo, orgánico.

En el Crátilo el Sócrates platónico compara las palabras a la pintura, el discurso al cuadro dibujado por el pintor, y la realidad aparece concebida como el modelo de ambas artes. Pues bien, el excelente cuadro lingüístico, cuya excelencia depende -dice Sócrates- tal vez del arte onomástica o tal vez del arte retórica o la que sea, ha de ser similar a la representación de un ser vivo realizada por un pintor. Ha de ser como la representación de un ser vivo, grande, hermoso y entero:

como los pintores que quieren plasmar semejanzas en sus cuadros unas veces sólo les aplican tinta de púrpura, otras en cambio alguna otra de las sustancias colorantes, y hasta en determinada ocasión mezclan muchas, como, por ejemplo, cuando preparan el color de la piel del varón o cosa parecida - según parezca, creo yo, que el retrato necesite de cada sustancia colorante-, así también nosotros aplicaremos las letras a las cosas, a una sola la letra única que parezca necesitar, o un grupo numeroso de ellas, haciendo lo que se llama sílabas y luego conjuntando sílabas, de las cuales se componen los nombres y los verbos. Y de nuevo a base de los nombres y los verbos constituiremos ya un ensamblaje grande, hermoso y en-

${ }^{57}$ Arist. Po. 1450b 34. 
tero, como allí el ser vivo reproducido por la pintura, aquí el discurso reproducido por el arte onomástica, la retórica o el arte que sea. ${ }^{58}$

Aquí tenemos expuesta la idea de que nombrar una realidad es mimar la esencia de lo nombrado y que cada letra de la palabra con que se mima guarda una relación de semejanza con la realidad y que el discurso resultante de la conjunción de letras, sílabas y palabras - nombres y verbos-, es (o tiene que ser) tan orgánica, hermosa, entera y unitaria como la buena pintura que acierta a reproducir el modelo de un ser vivo orgánico, unitario, bello, grande y proporcionado también él. La verdadera esencia de las cosas y de los seres vivos reales son sus "formas", las antiguas ideas platónicas que ahora, en la nueva metafísica de Aristóteles, habitan entre nosotros. Por consiguiente, la poesía, que es una réplica de la realidad, un artefacto, ha de ser tan unitaria, coherente y tan bien formalizada como las cosas y los seres vivos reales de la Naturaleza.

Creo que este pasaje del Crátilo es importante para detectar y seguir las huellas platónicas que descubrimos en la Poética aristotélica, sobre todo si se combina con el esencial del Fedro que previamente expusimos. En ambos se expresa con meridiana claridad la relación estrecha de la sústasis con la integridad, la proporción de las magnitudes y la belleza del objeto resultante de la producción artística, un objeto compuesto de partes bien trabadas como un ser vivo de la naturaleza.

En esta concepción platónica de la trabazón orgánica de la obra de arte y por tanto del discurso poético hay, por tanto, dos claves: una, la organicidad o carácter orgánico (de cuerpo vivo) de la obra de arte; y dos, la vinculación de la impresión de belleza o satisfacción estética a la organicidad que aúna las cualidades del orden, la proporción y la simetría. Lo bello sería

58 PI. Cra. $424 d 7$. 
aquello que encierra las cualidades del ser vivo orgánico que son precisamente el buen orden, la perfecta simetría y la definición precisa de sus partes. Al igual que en el animal vivo distinguimos la cabeza, el cuerpo central y las extremidades, pero cada una de sus partes no sólo se distingue de las demás, sino que además está proporcionada con respecto a las otras y al conjunto en que se integra, es decir, está ordenada y en perfecta simetría, del mismo modo en la obra de arte las partes ordenadas, simétricas y bien definidas son las que producen la satisfacción estética con que percibimos el conjunto.

Vayamos a la búsqueda de las dos claves: en un pasaje de la Poética aristotélica que ya hemos transcrito, aunque sólo parcialmente, y que versa acerca de la comparación de la obra poética con un ser vivo, Aristóteles emplea no sólo la voz zôion, "ser vivo", sino además sôma, "cuerpo de un ser vivo", hecho que de ninguna manera puede considerarse baladí. Veámoslo:

es más: puesto que lo hermoso, animal o toda cosa que lo sea, compuesto de algunas partes, no sólo debe tenerlas ordenadas, sino también contar con una cierta extensión que no sea cualquiera al azar, pues la belleza consiste en la medida y en el orden, por lo cual no puede resultar hermoso ni un animal demasiado pequeño (pues su contemplación se confunde al aproximarse al tiempo imperceptible), ni tampoco excesivamente grande (pues no se produce la contemplación en un mismo momento, sino que se les escapa a la contemplación de los observadores la unidad y la totalidad), como, por ejemplo, si el animal midiese diez mil estadios, en consecuencia, al igual que en los cuerpos y en los animales se requiere que posean una cierta extensión y que ésta sea abarcable en una mirada, así también en los argumentos es menester que tengan una extensión y que ésta sea abarcable por la memoria. ${ }^{59}$

${ }^{59}$ Arist. Po. $1450 \mathrm{~b} 34$. 
Creo que éste es un pasaje fundamental en la Poética porque contiene las dos claves indicadas, la de la organicidad (y ya podemos decir "corporeidad" puesto que se lee bien claramente en el texto "al igual que en los cuerpos y en los animales") del discurso poético, y la de las tres cualidades de la belleza producida por la mencionada organicidad que son el orden, la proporción y la simetría de las partes dentro del todo unitario que es la obra poética.

¿Qué quiere decir eso de "al igual que en los cuerpos y en los animales"?

No puede querer decir más que una cosa, a saber: que el cuerpo de un ser vivo es el más alto grado de organicidad posible en este mundo sublunar y que la obra de arte, la obra poética debe alcanzar ese mismo nivel para ser a justo título una obra poética que esté bien, que esté bien lograda. No olvidemos que la Poética aristotélica es un arte, o sea, un sistema de conocimientos teorético-práctico, descriptivo y normativo a un tiempo:

acerca de la Poética en sí misma y sus especies, de la función de cada una de ellas, y de cómo hay que entramar los argumentos si es que se pretende que la composición poética resulte bien, y, aún más, de cuántas y cuáles partes consta, e igualmente acerca de todos los demás puntos que atañen a la misma línea de investigación, tratemos empezando, como es natural, primero por los primeros. ${ }^{60}$

Aristóteles nos define el contenido de su tratado y de inmediato estamos ante el concepto de sústasis, el "entramado", el ensamblaje de las piezas dentro del todo, que tiene como realización suprema el cuerpo del animal o ser vivo compuesto de partes orgánicas. Este concepto fundamental aparece ya en las primeras líneas de la Poética porque su autor quiere hacernos

${ }^{60}$ Arist. Po. 1447a 8. 
notar que el texto que nos of rece no es más que el arte que describe esta organicidad y enseña a reproducirla en una obra poética de la que se espera un resultado exitoso.

Pues bien, el arte poética nos enseña a componer poemas que sean como "cuerpos de seres vivos, seres orgánicos", o sea, "compactos", con palabras, y el arte retórica, por su parte, nos enseña asimismo a disponer retóricamente (el término específico en griego antiguo es táttein) las relaciones o exposiciones de los hechos de manera que resulten "como cuerpos de seres vivos, seres orgánicos" o sea, "compactos".

Es éste un concepto de origen platónico que Aristóteles transmitió a la escuela peripatética a través de la ecuación cuerpos=animales que percibimos en la frase "al igual que en los cuerpos y en los animales". 61

De este modo se explica que el autor de la Rhetorica ad Alexandrum, que es posterior y sin ninguna duda depende del Estagirita, emplee la voz somatoeidés con el significado de "consistente", "compacto", “orgánico", un adjetivo compuesto empleado también por Teofrasto, ${ }^{62}$ el discípulo de Aristóteles que vivió, como - a nuestro juicio por lo menos- el autor de la Rhetorica ad Alexandrum, a finales del siglo Iv y comienzos del siglo II a. J. C. Este mismo adjetivo, que en la transmisión manuscrita con cierta frecuencia se confunde con la variante somatódes, de igual significado, aparece tres veces en la Rhetorica ad Alexandrum para designar lo "compacto", "consistente", "orgánico" o "sistemático. 63

61 Arist. Po. 1451 a 3.

62 Thphr. $H A$ V, 9, 3 "la llama más viva de todas la produce la vegetación arbustiva, pues de ella no resultan carbones en absoluto por el hecho de no tener la consistencia debida". Thphr. Ign. "puesto que lo más consistente y compacto, una vez inflamado, resulta más caliente".

${ }^{63} \mathrm{Rh}$. Al. $1438 \mathrm{~b} 22$ "y si los hechos son moderados en número y no son conocidos, debemos colocar la relación de ellos o su exposición o su presentación introductoria en forma de discurso compacto (somatoeidés) inmediatamente después del proemio". $R h$. Al. 1436a "y que en las diferentes especies de oratoria hay 
La organicidad y cohesión de la obra poética es un tema teórico de reflexión que encaja perfectamente en la metafísica platónica, luego en la aristotélica, y, más tarde, como acabamos de ver entra a formar parte de los dogmas o principios básicos de manuales de arte tan poco filosóficos ya como la Rhetorica ad Alexandrum.

En el platónico Timeo, el astrónomo pitagórico que sustituye como protagonista al Sócrates de los anteriores diálogos, pretende dejar claro que el número, la idea más abstracta, genérica y universal que concebirse puede, es la explicación del mundo y que un dios bueno, a partir de material preexistente, modeló el mundo poniendo inteligencia en las almas y almas en los cuerpos de los seres vivos.

Este mundo, al que se refiere Platón, es un mundo entero, unitario, un animal bien cohesionado, orgánico y visible, que abarca en su seno a todos los demás animales. Es, además, esférico, redondo, bien terminado, sin aristas ni huecos ni pies ni manos, que gira con el movimiento más completo y perfecto, que es el circular. Y todas las partes y elementos que componen este mundo están combinados en él de manera proporcional y armónica.

Pues bien, a ese mundo platónico modelado por Dios al contemplar las Ideas, que son como el patrón de la eternidad, Aristóteles lo colocó exactamente en nuestro entorno, en el cotidiano mundo en el que nos movemos y lo contempló con una visión a la vez empírica y platónica. Así, vio en él los cuerpos y las "formas" de los cuerpos, las almas inseparables de los cuerpos, ${ }^{64}$ esas almas o "formas" comparables a las Ideas platóni-

que disponer los discursos orgánicamente (somatoeidés) y de qué partes hay que usar las primeras y cómo hay que usar de ellas mismas, eso es lo que voy a explicar de nuevo". Rh. Al. 1442 b 30 "de la misma manera trataremos también las narraciones de los hechos: o bien las ligaremos al proemio o haremos ver que son justas y creibles a lo largo de sus partes o las produciremos como conjuntos orgánicos (somatoeidés) centrados en sí mismos".

64 Arist. de An. 413a. 
cas en cuanto que dan unidad a los cuerpos, los organizan, les comunican su esencia, los caracterizan como sustancias ${ }^{65} \mathrm{y}$, por si esto fuera poco, configuran su "causa final". ${ }^{66}$ Las plantas, por ejemplo, se componen de partes, pero son unitarias, orgánicas, funcionales porque, merced al alma, que es a la vez la "forma" y la "causa final" que las anima, les dota de esencia, finalidad y funcionalidad y así realizan funciones orgánicas, totales, integrales y bien enderezadas a un fin claro, como, por ejemplo, la autoalimentación.

Pues así debe ser la tragedia o la obra poética ideal, bien unitaria, bien funcional, bien formalizada y orgánica, para que, como el gran animal orgánico que es el mundo del Timeo y como las sustancias aristotélicas en las que más que ningún otro factor imperan la "forma" y la "causa final" como factores de unidad, produzcan el efecto que les es propio. Cuando el escultor traslada a la masa del mármol la imagen del modelo que alberga en su mente, esa "forma" y "causa final" dan unidad y sigularidad a la pieza y ocupan el lugar de la Idea de Belleza del universo platónico. Pero si la "forma" es el alma respecto del cuerpo de un ser orgánico, todo sigue siendo igual pero el grado de unidad alcanzado es mayor, porque gracias a esa nueva "forma" y "causa final" una parte no puede funcionar sin el todo, el ojo no puede ver aislado y funcionando por su cuenta. Así es la obra poética, un ser vivo, orgánico, unitario, en el que las partes no pueden alterarse ni ser suprimidas caprichosamente, porque ello repercutiría necesariamente en el todo. ${ }^{67}$

Toda esta lucubración es filosofía pura —casi teología - basada en el fundamento común de la metafísica aristotélicoplatónica. En la Poética aristotélica hay, pues, junto a innegables observaciones empíricas, principios que derivan de la más

\footnotetext{
${ }^{65}$ Arist. de An. 412a-b.

${ }^{66}$ Arist. de An. 414a.

${ }^{67}$ Arist. Po. 1451a 30.
} 
acendrada o acrisolada metafísica platónica. El poeta es más filósofo que el historiador ${ }^{68}$ porque expresa, no lo que meramente es o fue, sino lo que pudiera haber sido en virtud de la necesidad o la probabilidad. Está más cerca de las ideas, de las “formas" de las cosas por las que adquirimos el conocimiento de la realidad. El poeta aristotélico lee la realidad mejor que el hombre corriente porque contempla las ideas, las "formas" inmanentes de las cosas y así es capaz de hacer metáforas, o sea de percibir lo semejante entre cosas aparentemente muy distintas y distantes, ${ }^{69}$ cosas a simple vista irreconciliables y difíciles de conectar. ${ }^{70} \mathrm{El}$ poeta aristotélico es un filósofo que contempla la realidad auténtica de las cosas que no está en su individualidad sino en sus ideas o "formas" inmanentes. Es así como puede llamar a la "vejez" "atardecer de la vida" y definir la "tarde" como la "vejez del día"."

Un filósofo - dice Aristóteles en la Metafísica-debe teorizar sobre toda cosa. ${ }^{72}$ Ahora bien, en la Poética Ariștóteles hace algo más que teorizar, puesto que un arte, una tékhne, como lo es la Poética, es teoría y prạ́ctica. Por eso en esta obrita Aristóteles no se priva de dar normas, de prescribir (con frecuencia leemos en el texto: "hay que hacer esto", "es menester esto otro", "hay que aspirar a tal o cual meta" etc.). ${ }^{73}$ Los ejemplos citados en la nota a

${ }^{68}$ Arist. Po. $1451 \mathrm{~b} 5$.

${ }^{69}$ Arist. Rh. 1412a 12.

${ }^{n}$ Arist. Po. 1458a 27.

"Arist. Po. 1457b 22.

${ }^{n}$ Arist. Metaph. 1004a 34.

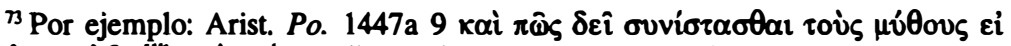

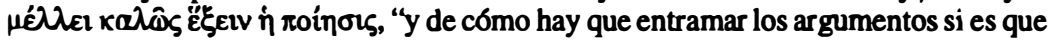
se pretende que la composición poética resulte bien". Arist. Po. 1450b 21. Dia-

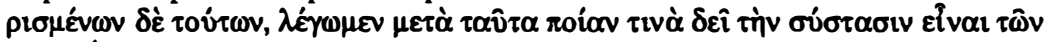

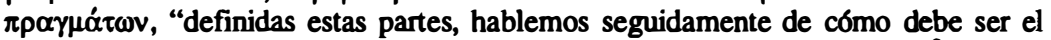

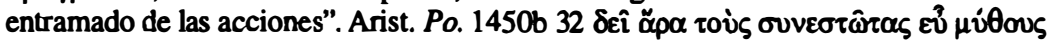

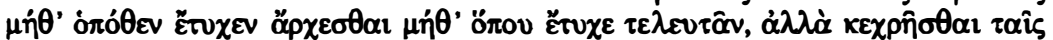

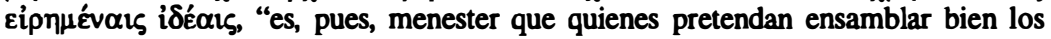
argumentos no los empiecen ni terminen donde les cuadre, sino que hagan uso

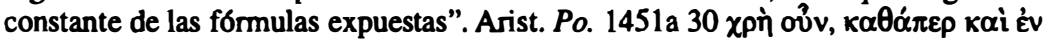


pie de página, a base de formas verbales impersonales de obligatoriedad, necesidad o precisión son típicas del estilo de los manuales técnicos que los sofistas entre otros hicieron proliferar. Esta fraseología encierra normas y consejos prácticos derivados de la

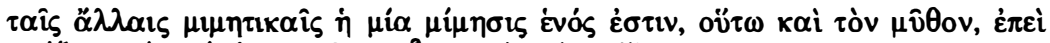

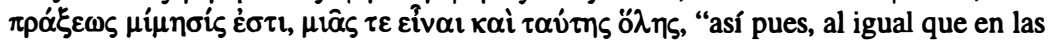
demás artes de imitación la unidad de la imitación resulta de la unidad de su objeto, así también es preciso que el argumento, puesto que es imitación de una sola acción,

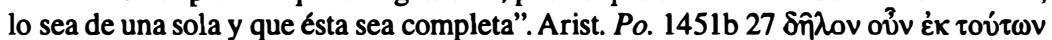

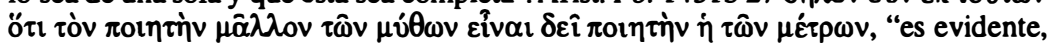
por tanto, que el poeta debe ser más bien creador de los argumentos que de los

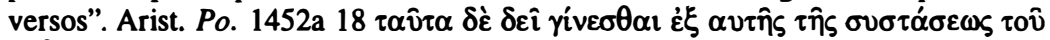

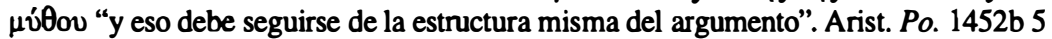

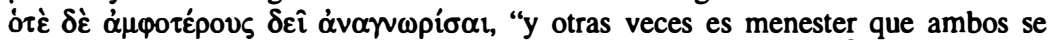

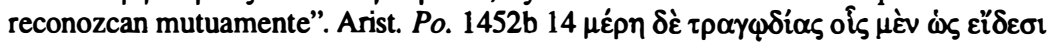

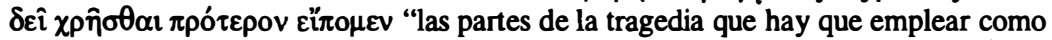
aspectos inseparables de ella, ya las dijimos antes". Arist. Po. $1452 \mathrm{~b} 28$ " $\Omega v \delta \dot{v} \delta \varepsilon \hat{\imath}$

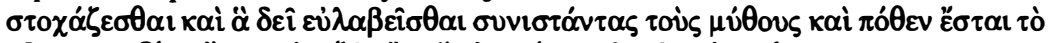

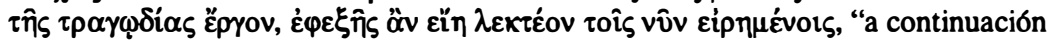
de lo que acabamos de decir, habría que hablar de aquello a lo que deben aspirar y de aquello de lo que se deben guardar los compositores de argumentos, así como de cuál es el origen del efecto de la tragedia". Arist. Po. 1452b $34 \pi p \hat{n} \tilde{\tau}$.

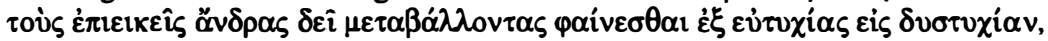
"es evidente, en primer término, que ni deben mostrarse los individuos equitativos

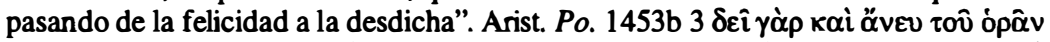

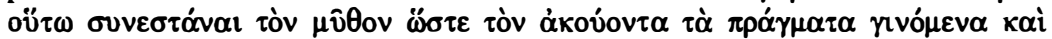

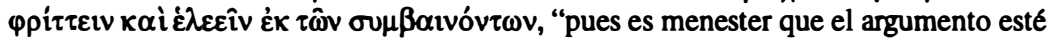
trabado de tal forma, que, aun sin verlos, el que escuche el acaecimiento de los hechos se estremezca y sienta compasión a raíz de los acontecimientos". Arist. Po. $1453 \mathrm{~b} 10$

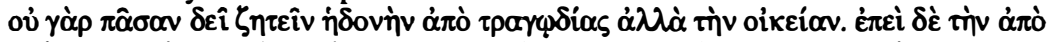

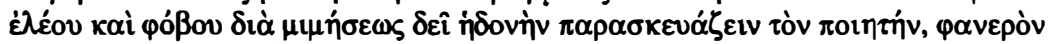

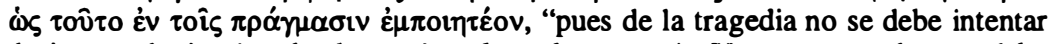
derivar cualquier tipo de placer, sino el que le es propio. Y puesto que el poeta debe procurar, a través de la imitación, el placer derivado del terror y la compasión, es evidente que ese propósito ha de realizarse en la entraña misma de los hechos". Arist.

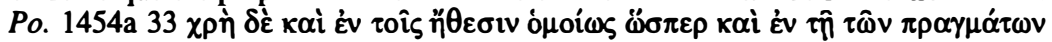

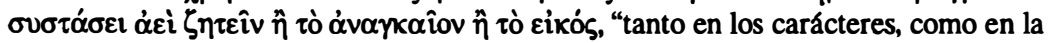
trabazón de las acciones, es igualmente preciso buscar siempre o lo necesario o lo

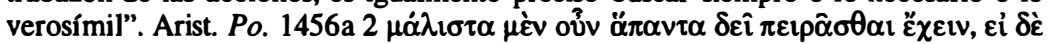

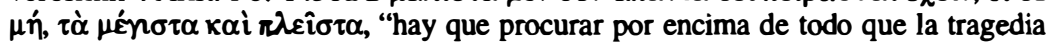
contenga todas estas partes, y, si no, las más importantes y la mayor parte de ellas".

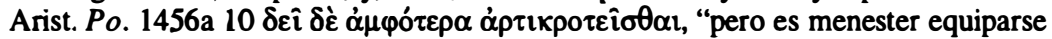
bien en ambas partes", Arist. Po. 1456a 10 xp

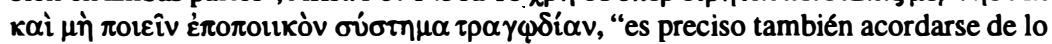
que se ha dicho en repetidas ocasiones y no hacer de la tragedia una composición épica", etc. 
teoría pero basados al mismo tiempo en la experiencia. Por ejemplo: los poetas autores de poemas épicos de acciones episódicas y dispersas como la Heracleida o la Teseida se han equivocado, mientras que Homero sobre todo con la unitaria Ilíada acertó plenamente. ${ }^{74} \mathrm{El}$ hecho de que a veces es necesaria una anagnórisis mutua de dos personajes se apoya en el hecho empírico de que en la tragedia euripidesca de la Ifigenia entre los tauros, admirable para el Estagirita al igual que el Edipo Rey sofocleo, Orestes reconocía a su hermana Ifigenia cuando ésta entregaba a Pílades una carta para su hermano, pero ella no reconoció a Orestes sino cuando este último decidió mostrar su identidad a través de sus palabras. ${ }^{75}$

Se coloca, así, Aristóteles valientemente entre la ciencia (epistéme) y la experiencia (empeiría), entre el saber teorético pleno y el rutinario saber hacer. Se coloca en los dominios de la tékhne combinando la empeiría con la epistéme.

A Platón sólo le satisfacía plenamente el saber teorético, su Discurso Verdadero (Alethès Lógos), que era pura epistéme. Pero a los sofistas les encantaban las artes, las tékhnai, las teorías aplicables. Pues bien, Aristóteles compone un arte, una tékhne, sobre la poesía, en la que se entreveran principios filosóficos, como la unidad esencial y la cohesión imprescindible de la obra poética, con inteligentes consejos prácticos derivados de la experiencia, como el de componer los argumentos colocándose previamente delante de los ojos las situaciones que van a ser representadas o el de emplear en toda poesía una dición clara pero no vulgar, ${ }^{76}$ consejos, todos ellos, que son de mucho provecho no sólo para el poeta, sino también para el orador.

En conclusión: La poética, la retórica, la mismísima teoría de la comunicación y la filosofía no están distanciadas unas de otras,

${ }^{74}$ Arist. Po. 1451a 20.

${ }^{75}$ Arist. Po. 1452 b 5.

${ }^{76}$ Arist. Po. 1455 a 21 y 1458 a 18 respectivamente. 
sino que se interpenetran. Esto es lo que hoy se piensa y en este siglo que empieza se seguirá pensando. Pero es también lo que pensaba el Estagirita que aplicó a la poética buena parte de la metafísica que de algún modo compartía con su maestro. También él afirmó que la poesía era más filosófica que la historia ${ }^{77}$ y que un poeta expresando una bella metáfora era como un buen filósofo inteligente capaz de ver relaciones entre cosas que al vulgo le parecen muy distantes entre sí. ${ }^{78}$

${ }^{77}$ Arist. Po. $1451 \mathrm{~b} 5$.

${ }^{78}$ Arist. Po. 1459a 6. 